\title{
Impacto da ação antrópica na degradação da mata ciliar do trecho perenizado do Rio Trussu, Ceará, Brasil*
}

\author{
Francisco Johnson Albuquerque Batista, ${ }^{1,2}$, José Ribeiro de Araújo \\ Neto $^{3}$, Helba Araújo de Queiroz Palácioํㅜ, Geovane Barbosa Reinaldo \\ Costa $^{1}$, Maria Monaliza de Sales ${ }^{1}$
}

${ }^{1}$ Instituto Federal do Ceará. Campus Iguatu. Rua Deoclécio Lima Verde, S/N. Iguatu-CE. (CEP 63500-000). ${ }^{2} E-m a i l:$ franciscojohnsonwar@gmail.com.

${ }^{3}$ Universidade Federal do Ceará. Departamento de Engenharia Agrícola. Campus do PICI. Bloco 804. Fortaleza-CE. (CEP 60450-760).

Resumo. O bioma Caatinga vem, ao longo das últimas décadas, sendo devastado, sendo utilizada para áreas com pecuária intensiva e agricultura. E a mata ciliar dos corpos hídricos tornam-se as áreas degradadas que sofrem maior pressão antrópica. Assim, o objetivo deste estudo foi avaliar o impacto da ação antrópica na degradação da mata ciliar do trecho perenizado do Rio Trussu num determinado intervalo de tempo (2003 e 2013). O estudo foi desenvolvido no Vale do Rio Trussu que se encontra localizado na Bacia do Alto Jaguaribe, Ceará, Brasil. O trecho perenizado do Rio Trussu tem importante papel no abastecimento de recursos hídricos na região, sendo destinadas às águas para múltiplos usos. Para classificação do uso e ocupação do solo nos diferentes períodos de monitoramento foram utilizadas imagens do satélite Landsat 5 para o ano de 2003 e para o ano 2013 Landsat 8-OLI. Nos resultados obtidos observa-se que, para o ano de 2003, a classe de uso da caatinga densa e rala ocupavam $37,5 \%$ e para o ano de 2013 foi $21,6 \%$, e para a classe antropizada foi de 61,6 e 77,9\%, enquanto para os corpos hídricos foi 0,9 e 0,5\%, respectivamente. Observou-se com este estudo uma dinâmica acelerada no comportamento da degradação da cobertura vegetal na mata ciliar do Rio Trussu, com a substituição progressiva das áreas de caatinga densa por áreas de caatinga rala e antropizada.

Palavras-chave: Degradação ambiental; Uso do solo; Código florestal; Semiárido.

Abstract. Impact of human activities on the degradation of riparian forest of perennial stretch of the River Trussu, Ceará, Brazil. The Caatinga biome has, over the past decades, being devastated, being used for areas with intensive livestock and agriculture. And the riparian vegetation of water bodies become degraded areas suffering most anthropogenic pressure. The objective of this study was to evaluate the impact of human action on the degradation of riparian forest of perennial stretch of the River Trussu between 2003 and 2013. The study was conducted in Trussu River Valley, located in the Alto Jaguaribe Basin, Ceará, Brazil. The perennial stretch of River
Recebido:

29/07/2016

Aceito:

29/09/2016

Publicado:

30/09/2016

Acesso Aberto

Artigo completo

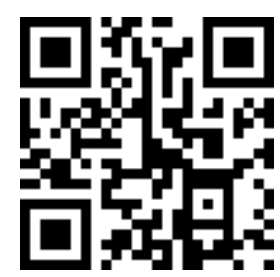

ORCID

๑) 0000-0001-9016-9843

Francisco Johnson

Albuquerque Batista

(D) 0000-0001-7118-1644

José Ribeiro de Araújo

Neto

(1) 0000-0002-5105-4821

Helba Araújo de

Queiroz Palácio

(1) 0000-0001-7118-1644

Geovane Barbosa

Reinaldo Costa

(1) 0000-00001-9856-7774

Maria Monaliza de Sales

\footnotetext{
*Apresentado no V Congresso Brasileiro de Educação Ambiental Aplicada e Gestão Territorial, Fortaleza/CE, 8 a 11/06/2016.
} 
Trussu plays an important role in the supply of water resources in the region, being the waters intended for multiple uses. To use classification and land use in different periods of monitoring were used Landsat 5 satellite images for the year 2003 and Landsat 8-OLI for the year 2013. The results shows to the year 2003, the use class of dense and sparse scrub occupied $37.5 \%$ and for the year 2013 was $21.6 \%$, and the anthropic class was 61.6 and $77.9 \%$, while for water bodies was 0.9 and $0.5 \%$, respectively. Also was observed an accelerated dynamic behavior of the degradation of vegetation in the riparian forest of River Trussu, with the gradual replacement of areas of dense scrub for areas of sparse scrub and disturbed.

Keywords: Environmental degradation; Use of the soil; Forest Code; Semiarid region.

\section{Introdução}

A ocupação do Brasil caracterizouse pela falta de planejamento e consequentemente pela destruição dos recursos naturais, devido a falsa ideia de que esses recursos eram inesgotáveis, estimulando um desenvolvimento desordenado, sem compromisso com o futuro (Marques e Barbosa, 2006). Esta ocupação desordenada vem degradando muitos biomas, principalmente a Caatinga que, devido a sua localização na região semiárida, potencializa a degradação.

Apesar de sua importância, a Caatinga vem sendo gradativamente devastada, com a supressão da vegetação nativa para a exploração da madeira, implantação de pecuária intensiva, agricultura nas partes mais úmidas e para outros fins de menor interesse socioeconômico. Este tipo de exploração em um ambiente tão pouco conhecido e complexo poderá levar a um processo irreversível de degradação (Silva et. al., 2004).

Segundo o MMA (2002), a Caatinga é um dos biomas brasileiros mais alterados pelas atividades humanas. É nessa região que estão localizadas as maiores áreas em processo de desertificação.

A exploração predatória dos recursos naturais, a falta de práticas adequadas das atividades agrícolas, aliada as condições climáticas do semiárido com longos períodos de estiagem, tem degradado a cobertura vegetal e acarretado o assoreamento dos rios e reservatórios, pela erosão dos solos. A atividade humana desordenada vem comprometendo a vida do homem, a sustentabilidade do bioma caatinga e intensificando o processo de desertificação, principalmente onde os solos apresentam condições físicas menos propícias a exploração agropecuária e colocando em risco as áreas ainda preservadas, porém vulneráveis a ação humana (Sousa et al., 2007), incluindo matas ciliares que se tornaram alvo de vários tipos de degradação.

A vegetação ciliar é definida como sendo o conjunto de formações que ocorre adjacente ou bordeando as margens dos corpos d'água, ao longo dos quais podem estender-se por dezenas de metros a partir das margens e apresentar marcantes variações na composição florística e na estrutura, dependendo das interações que se estabelecem entre o ecossistema aquático e o ambiente terrestre adjacente (Lacerda et al., 2007). Apesar desse tipo de vegetação ser de extrema importância, vem sendo degradado de forma intensa. Por se tratar de um ambiente com maior umidade, sua vegetação é frequentemente retirada para 0 estabelecimento de agricultura (Araújo, 2009).

Sendo assim, diante do exposto, o objetivo deste trabalho é avaliar o impacto da ação antrópica na degradação da mata ciliar do trecho perenizado do rio Trussu, Ceará, Brasil, em um determinado intervalo de tempo (2003 e 2013), utilizando-se sensoriamento remoto e ferramentas de 
geoprocessamento para classificar diferentes usos e ocupações do solo.

\section{Material e Métodos}

O estudo foi desenvolvido no Vale do Rio Trussu (24 km), o qual é perenizado artificialmente pelo açude de mesmo nome. A área em estudo encontra-se localizada na Bacia do Alto Jaguaribe (Figura 1), na região Centro-Sul do Ceará. A vazão regularizada para a perenização da parte baixa do vale é variável entre 0,2 a 4,2 $\mathrm{m}^{3} . \mathrm{s}^{-1}$, sendo a mesma liberada pelo Açude Trussu o qual possui uma capacidade de armazenar $301.000 .000 \mathrm{~m}^{3}$. O referido rio drena uma bacia hidrográfica de $1.590 \mathrm{~km}^{2}$.
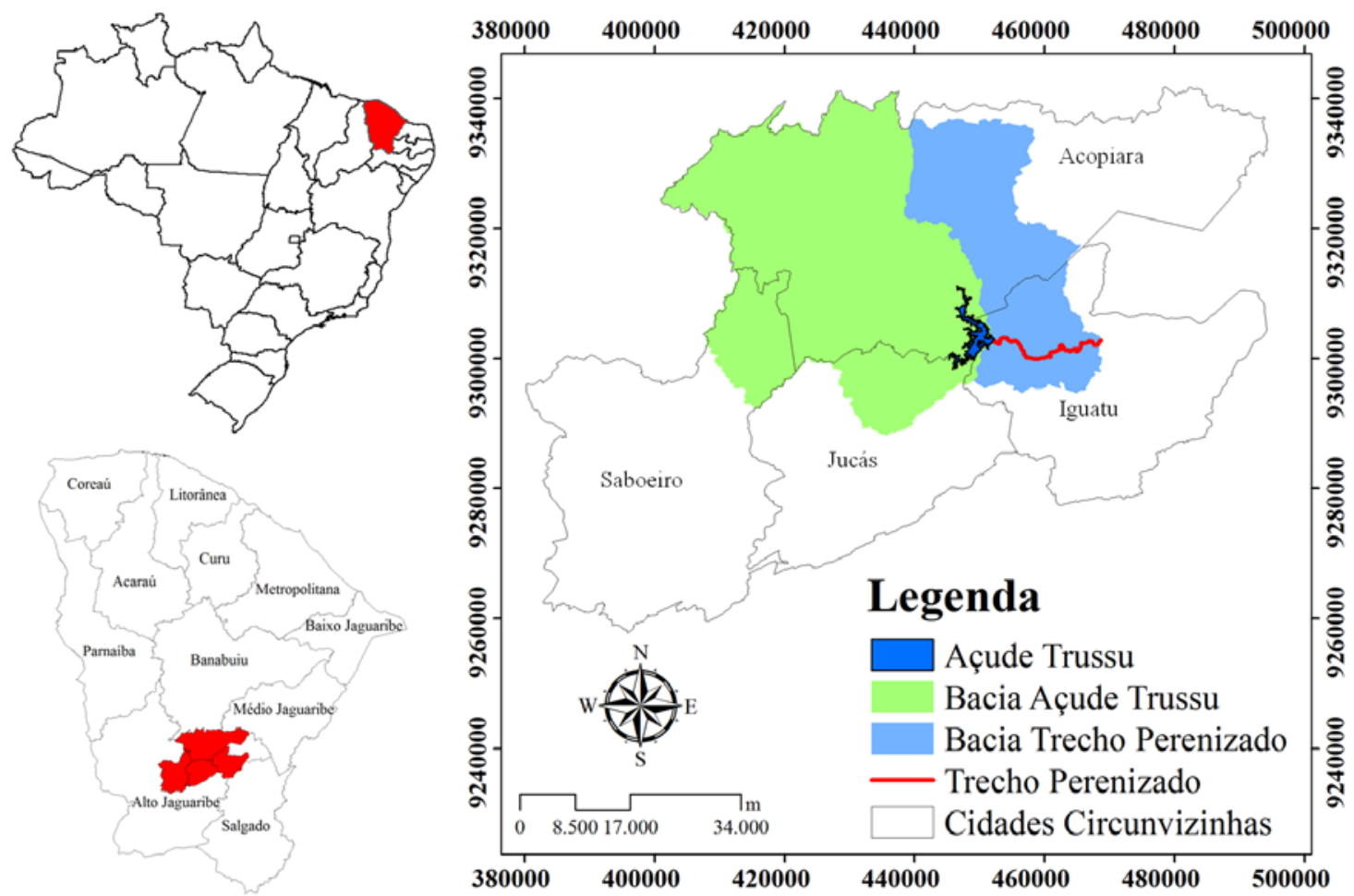

Figura 1. Localização da Bacia Hidrográfica do Açude Trussu e do trecho perenizado do Rio Trussu, na Bacia do Alto Jaguaribe, Ceará, Brasil, bem como a localização do rio perenizado de $24 \mathrm{~km}$.

O clima da região é do tipo BSw’h' (semiárido quente), de acordo com a classificação climática de Köppen, com temperatura média sempre superior a $18{ }^{\circ} \mathrm{C}$ no mês mais frio. $\mathrm{O}$ Índice de Aridez elaborado por Thornthwaite (1948) é de 0,44 , classificando-se como semiárido. A evapotranspiração potencial média é de 2.059 mm.ano ${ }^{-1}$, a precipitação média histórica na região é de 994 mm (Funceme, 2010), com 88\% da precipitação anual registrada no período de verão-outono (janeiro a abril), e 65\% nos meses de março a abril, mostrando uma alta pluviosidade concentrada em um curto período do ano. Em adição a esta concentração, a região é caracterizada por muitas horas de insolação (2.945 h ano-1).

O trecho perenizado do Rio Trussu tem importante papel no abastecimento de recursos hídricos na região, sendo destinadas as águas para diversos usos: abastecimento humano, irrigação, industrial, aquicultura, turismo e lazer. De acordo com a Companhia de Gestão de Recursos Hídricos do Ceará (COGERH) são 104 outorgantes cadastrados no Rio Trussu, sendo o principal uso outorgado à 
agricultura irrigada, representando 95\% das outorgas. O principal método de irrigação utilizado é aspersão representando $82 \%$ das áreas irrigadas, sendo 9\% inundação e 9\% microaspersão. Totalizando uma área irrigada outorgada de 160,3 ha, sendo as principais culturas, pastagem, milho, feijão, cana de açúcar, fruticultura (goiaba, melancia, uva, entre outros).

Segundo o mapa de solos, as áreas estudadas encontram-se na mancha de solo caracterizado como Neossolo Flúvico. Os Neossolos nesta região são compostos por sedimentos cáusticos de granulometria variada, desde argilas até areias grosseiras, apresentando uma litologia com conglomerados intercalados com silte e formação geológica Rio Piranhas (Funceme, 2016).

Para realização do estudo foi utilizada a faixa de mata ciliar do trecho perenizado do rio Trussu, que corresponde a uma extensão de $24 \mathrm{~km}$. Para cálculo da largura da mata ciliar utilizou-se os critérios definidos conforme a Lei $\mathrm{n}^{\circ}$ 12.651/2012 (Brasil, 2012). De acordo com o novo código florestal, matas ciliares são conceituadas como "área protegida, coberta ou não por vegetação nativa, com a função ambiental de preservar os recursos hídricos, a paisagem, a estabilidade geológica e a biodiversidade, facilitar o fluxo gênico de fauna e flora, proteger o solo e assegurar 0 bem-estar das populações humanas" (art. $3^{\circ}$, II, Lei $12.651 / 2012$ ) e são definidas na referida lei como Área de Preservação Permanente (APP) (Santos et al., 2013). Para rios como o Trussu, com extensão de até $10 \mathrm{~m}$ na sua largura, é adotada uma faixa de APP de $30 \mathrm{~m}$ as margens direita e esquerda do rio perenizado, considerando o leito regular do rio.

Para classificação do uso e ocupação do solo nos diferentes períodos de monitoramento foram utilizadas imagens do satélite Landsat $5^{\mathrm{TM}}$, de 26 de outubro de 2003, bem como, imagem do satélite Landsat 8-OLI, de 19 de setembro de 2013. Ambas as imagens foram adquiridas gratuitamente junto à Divisão de Geração de Imagens (DGI), do Instituto Nacional de Pesquisas Espaciais (INPE), e United States
Geological Survey (USGS), respectivamente.

$\mathrm{Na}$ etapa de processamento e análise das imagens foram tomados como ferramentas os softwares ArcMap 9.3, ENVI 4.7, ERDAS IMAGINE 9.2, Google Earth 7.1.2 e X-6Scorr. Foram realizadas correções atmosféricas das imagens e após este procedimento iniciou-se a etapa de composição de bandas. A composição escolhida para o satélite Landsat $5^{\mathrm{TM}}$ foi R4/G3/B2 (falsa cor). A composição do satélite Landsat 8-OLI foi R5/G4/B3, por abranger praticamente os mesmos comprimentos de ondas das bandas do satélite Landsat5, obtendo assim os mesmos resultados.

Para o levantamento do uso e cobertura do solo, foi utilizado o método de classificação supervisionado máxima verossimilhança (MAXVER). Para obter um resultado satisfatório na classificação das imagens com a utilização desse método, o classificador deve ter o prévio conhecimento da área que será levantada, além de realizar a seleção de um número significativo de pixels para as amostras de treinamento (Coelho et al., 2014). Dessa forma, as classes de uso e cobertura determinadas para que se pudesse entender a dinâmica que ocorre na Bacia Hidrográfica do Açude Trussu e do trecho perenizado do Rio Trussu foram água, área antropizada, caatinga densa e caatinga rala. Por fim, foi calculado o coeficiente de Kappa, bastante utilizado para se realizar a validação de classificações de imagens feitas a partir de técnicas de sensoriamento remoto.

\section{Resultados e Discussão}

Apresenta-se na Tabela 1 a distribuição espacial do uso e ocupação do solo da mata ciliar do trecho perenizado do Rio Trussu dos anos de 2003 e 2013. Observa-se que no ano de 2003 a soma das áreas de caatinga densa e rala ocupavam $37,5 \%$ da área total, enquanto a área antropizada foi de 61,6 \%. Já no ano 2013 a soma das áreas de caatinga densa e rala ocupavam $21,6 \%$ da área total, enquanto a área antropizada foi 77,9, evidenciando 
uma intensiva diminuição da vegetação de floresta na mata ciliar, composta por caatinga densa e rala. Tal progressão ao longo desses 10 anos, corrobora com a ideia apresentada por Bittencourt e Batista (2009) de que o processo de degradação destas áreas é antigo, com início a partir do desmatamento para implantação em campos de cultivo e pastagem, já que as áreas mais baixas (várzeas), localizam-se junto às margens do rio que são terras planas e férteis (Ferreira e Dias, 2004) o que refletiu diretamente no espelho de água, que aliado a outros fatores, passou de $0,9 \%$ em 2003, para 0,5\% em 2013.

Tabela 1. Área e percentual de uso e ocupação do solo na mata ciliar do trecho perenizado do rio Trussu, Ceará nos anos de 2003 e 2013.

\begin{tabular}{lcccc}
\hline \multirow{2}{*}{ Uso e Ocupação do Solo } & \multicolumn{4}{c}{ Mata ciliar do trecho perenizado do rio Trussu } \\
\cline { 2 - 5 } & \multicolumn{2}{c}{$\mathbf{2 0 0 3}$} & \multicolumn{2}{c}{$\mathbf{2 0 1 3}$} \\
\cline { 2 - 5 } & Área (ha) & $\mathbf{( \% )}$ & Área (ha) & $\mathbf{( \% )}$ \\
\hline Caatinga Densa & 44,8 & 31,4 & 15,7 & 11,0 \\
Caatinga Rala & 8,7 & 6,1 & 15,1 & 10,6 \\
Antropizada & 87,7 & 61,6 & 111,0 & 77,9 \\
Água & 1,3 & 0,9 & 0,7 & 0,5 \\
\hline Total & $\mathbf{1 4 2 , 5}$ & $\mathbf{1 0 0 , 0}$ & $\mathbf{1 4 2 , 5}$ & $\mathbf{1 0 0 , 0}$ \\
\hline
\end{tabular}

Comparando os dois anos em estudo, 2003 e 2013, é possível observar que as áreas com Caatinga densa as margens do Rio Trussu apresentaram uma queda de 20,4\%, representando a degradação ocorrente nestas áreas, que de acordo com a Lei $n^{\circ}$ 12.651/2012 é considerada APP, sendo esta uma área protegida, dotada de funções ambientais, que deve ser mantida conservada, com sua exclusiva exceção de supressão apenas em caso de utilidade pública ou interesse social.

Em resposta ao decréscimo de área de caatinga densa, tem-se o acréscimo de 6,4 ha de áreas de Caatinga rala, representando no ano de 2013 10,6\% da área total de mata ciliar. Enquanto que a área antropizada em ambos os períodos se apresentaram maiores que as demais áreas avaliadas, com acréscimo de 16,3\% neste período de 10 anos. Vieira et al. (2013) observaram em levantamento do uso e cobertura do solo da região semiárida do Brasil que $57 \%$ do território do Nordeste brasileiro representa áreas antropizadas, e que estas áreas eram ocupadas por caatinga, verificando assim uma acelerada degradação da mata nativa.
O decréscimo de 0,4\% das áreas com água, tem seu outro fator a precipitação média da região em que se encontra inserida a bacia do Rio Trussu, que no ano de 2003 teve valor de 777,9 $\mathrm{mm}$, enquanto que no ano de 2013 foi de $472,0 \mathrm{~mm}$, ou seja $39,32 \%$ a menos (Funceme, 2016).

Observa-se que no ano 2003 (Figura 2) a classe de uso do solo antropizada apresentou uma maior predominância, seguido de caatinga densa e alguns pontos de caatinga rala ao longo da mata ciliar do trecho do rio Trussu. A apresentação dos três estagio da vegetação ilustra o processo de degradação, que apesar de ainda apresentar vegetação densa, as mesmas estão vulneráveis a exploração. Esta predominância de área antropizada, é um cenário encontrado por vários pesquisadores como Ferreira e Dias (2004), Bittencourt e Batista (2009), Bailly et al. (2012), que descrevem que a instauração e evolução do desenvolvimento urbano e agrícola se deu em áreas marginais de cursos hídricos, causando a degradação destas áreas. Silva et al. (2014), ao mapear a alteração da cobertura vegetal na SubBacia do Rio Espinharas, no período de 
2000 a 2010, verificaram que $80 \%$ da área da sub-bacia em estudo, apresenta acentuado antropismo com trechos altamente degradados, revelando essas áreas como um produto de um quadro de degradação.

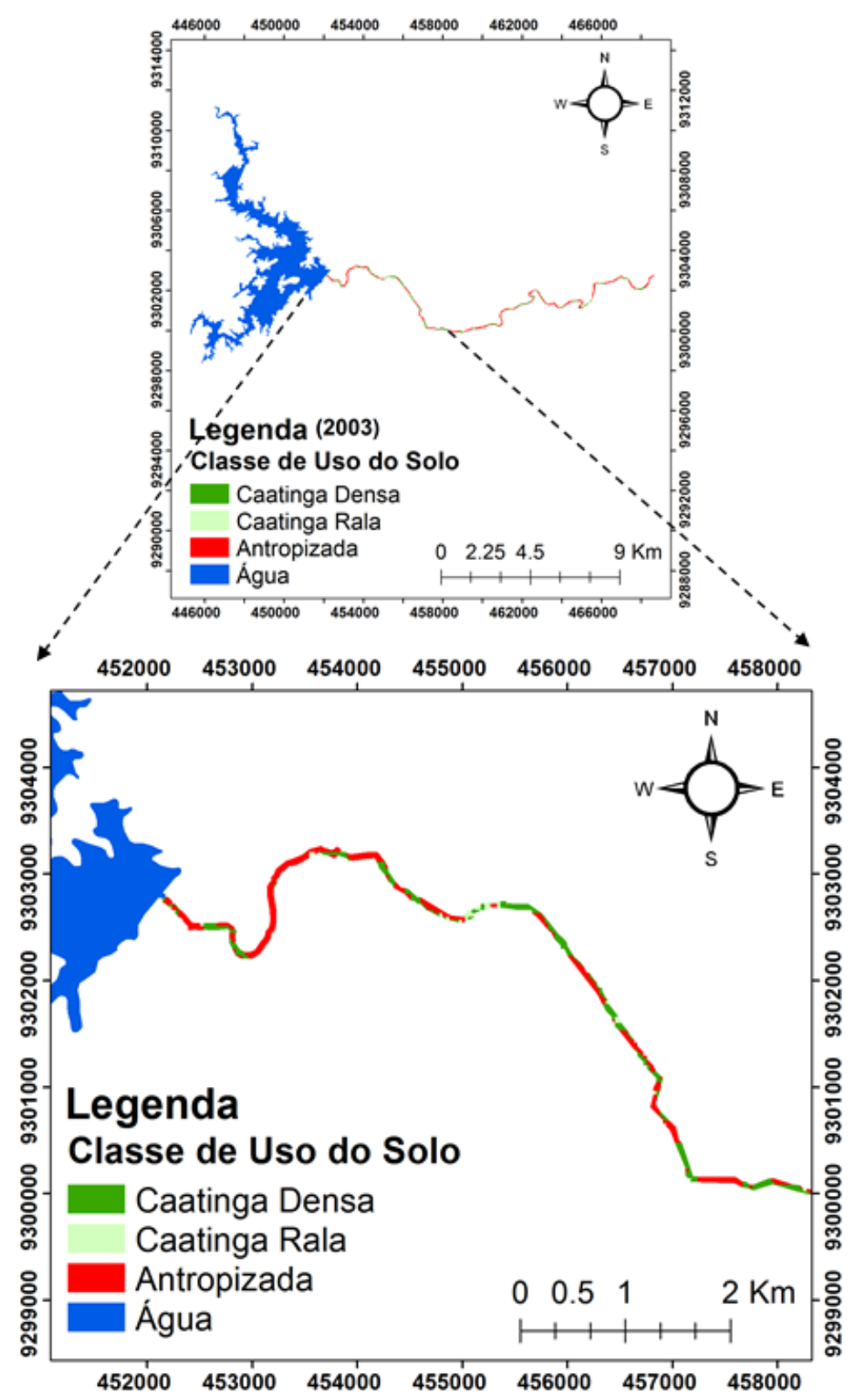

Figura 2. Uso e ocupação do solo na mata ciliar do trecho perenizado do Rio Trussu, Ceará, no ano de 2003: (a) trecho perenizado completo $24 \mathrm{~km}$ do Rio Trussu; e (b) zoom na parte alta do trecho perenizado do Rio Trussu. Datum: WGS 84. 
A classe de uso antropizada na mata ciliar do trecho perenizado do rio Trussu no ano de 2013, obteve um grande aumento na área total, em torno de 23,3 ha em relação ao ano de 2003 (Figura 3). O aumento está relacionado à influência antrópica sobre a vegetação, isto devido ao pastoreio extensivo, principalmente com bovinos, aliado à extração de material lenhoso para construção de cercas e para queima. A principal exploração é agropecuária, com o uso de fertilizantes nas pastagens e criação de animais. Também há presença de núcleos urbanos que contribuem com despejos de esgotos domésticos sem tratamentos. As áreas as margens do rio perenizado são intensamente aproveitadas com diversas culturas como cana-de-açúcar, arroz, olericultura, milho, feijão, algodão, pastagens (naturais ou artificiais), e em crescente aumento da fruticultura irrigada.

No ano de 2013, 10 anos após a primeira imagem (2003), a classe de uso de solo densa teve uma grande diminuição, perdendo 29,1 ha da área total, e um grande aumento da caatinga rala, 6,4 ha. Este aumento está relacionado a supressão de árvores de maior porte para fins de comercialização. Silva et al. (2014) afirmam que práticas como corte da vegetação para produção de estacas, carvão, lenha para uso doméstico ou comercial e o preparo da área para a agricultura favorecem a diminuição da vegetação Caatinga na região semiárida. As áreas anteriormente vulneráveis foram exploradas, deixando o corpo hídrico desprotegido, afetando a qualidade da água.
Martins (2001), e Rodrigues e Leitão Filho, (2000) afirmam que as matas ciliares tem a função de filtro, retendo sedimentos, nutrientes, defensivos agrícolas e outros poluentes que afetam a qualidade da água, além de melhorar a estrutura do solo através de suas raízes, colaborando para a infiltração de água.

\section{Conclusão}

Conclui-se neste trabalho que o uso e ocupação do solo na área de mata ciliar do trecho perenizado do rio Trussu, apresentou maior percentual de classificação de área antropizada nos dois períodos de avaliação 2003 e 2013, seguidos pelas classes de caatinga densa e rala. Verificou-se ainda uma dinâmica acelerada no comportamento da cobertura vegetal com a substituição progressiva das áreas de caatinga densa por áreas de caatinga rala e antropizada, evidenciando uma progressiva degradação da mata ciliar do trecho do Rio Trussu e grande pressão sobre os recursos naturais nestas áreas ao longo dos 10 anos.

\section{Agradecimentos}

Ao Instituto Federal de Educação, Ciências e Tecnologia do Ceará (IFCE), pelo apoio no desenvolvimento da pesquisa, e ao Conselho Nacional de Desenvolvimento Científico e Tecnológico (CNPq) pelo apoio financeiro.

\section{Declaração de conflito de interesses}

Os autores declaram não haver conflitos de interesses. 


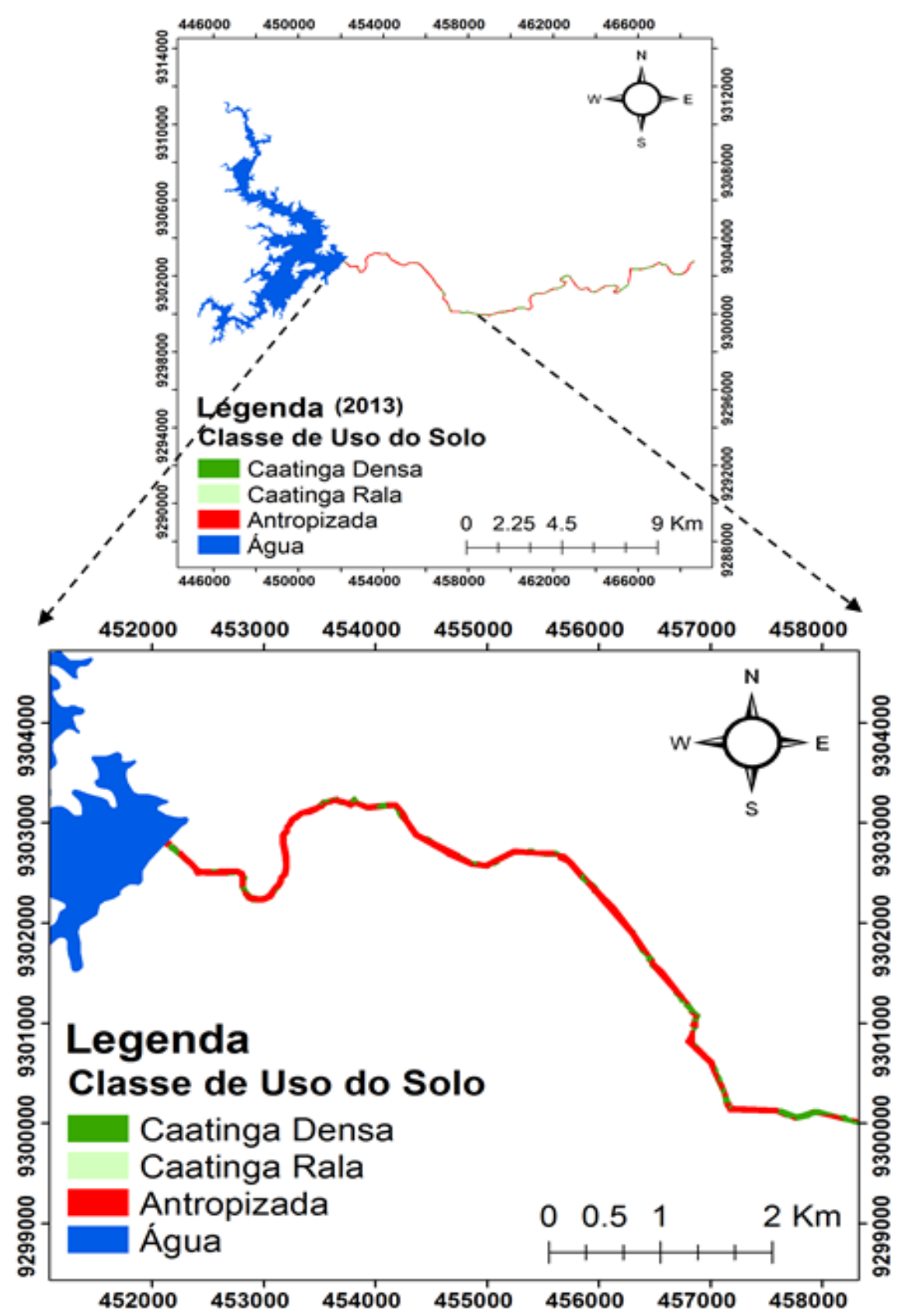

Figura 3. Uso e ocupação do solo na mata ciliar do trecho perenizado do Rio Trussu, Ceará, no ano de 2013: (a) trecho perenizado completo $24 \mathrm{~km}$ do Rio Trussu; e (b) zoom na parte alta do trecho perenizado do Rio Trussu. Datum: WGS 84.

\section{Referências}

Araújo, G. M. Matas ciliares da caatinga: florística, processo de germinação e sua importância na restauração de áreas degradadas. Recife: Universidade Federal Rural de Pernambuco, 2009. (Dissertação de mestrado).

Bailly, D.; Fernandes, C. A.; Silva, V. F. B.; Kashiwaqui, E. A. L.; Damásio, J. F.; Wolf, M. J.; Rodrigues, M. C. Diagnóstico ambiental e impactos sobre a vegetação ciliar da Microbacia do Córrego da Ponte, área de proteção ambiental do Rio Iguatemi, MS. Revista em Agronegócios e Meio Ambiente, v. 5, n. 2, p. 409-427, 2012.

Bittencourt, L. F. F.; Batista, G. T. Intervenção humana na mata ciliar do Rio Paraíba do Sul, Município de Caçapava, SP. Revista OKARA: Geografia em Debate, v. 3, n. 2, p. 223-347, 2009.

Brasil. Lei $\mathbf{n}^{\mathbf{0}}$ 12.651, de 25 de maio de 2012. Dispões sobre a proteção da vegetação nativa; 
altera as Leis $\mathrm{n}^{\text {os }}$ 6.938, de 31 de agosto de 1981, 9.393, de 19 de dezembro de 1996, e 11.428 , de 22 de dezembro de 2006; revoga as Leis $\mathrm{n}^{\text {os }} 4.771$, de 15 de setembro de 1965, e 7.754, de 14 de abril de 1989, e a Medida Provisória $\mathrm{n}^{\circ}$ 2.166-67, de 24 de agosto de 2001; e dá outras providências. Disponível em: <http://www.planalto.gov.br/ccivil_03/_ato2011 -2014/2012/lei/l12651.htm>. Acesso em: 15 ago. 2016.

Coelho, V. H.; Montenegro, S. M.; Almeida, C. D. N.; Lima, E. R.; Ribeiro Neto, A.; Moura, G. S. Dinâmica do uso e ocupação do solo em uma bacia hidrográfica do semiárido brasileiro. Revista Brasileira de Engenharia Agrícola e Ambiental, v. 18, n. 1, p. 64-72, 2014. http://dx.doi.org/10.1590/S141543662014000100009

Ferreira, D. A. C.; Dias, H. C. T. Situação atual da mata ciliar do Ribeirão São Bartolomeu em Viçosa, MG. Revista Árvore, v. 28, n. 4, p. 617-623, 2004.

Funceme - Fundação Cearense de Meteorologia e Recursos Hídricos. Séries pluviométricas do Ceará (1974-2008). 2010. Disponível em: $<$ http://www.funceme.br/>. Acesso em: 20 set. 2010.

Funceme - Fundação Cearense de Meteorologia e Recursos Hídricos. Séries pluviométricas do Ceará (1997-2006; 2007-2016). 2016. Disponível em: <http://funceme.br/app/ calendario/produto/acudes/media/anual?data=20 0311http://funceme.br/app/calendario/produto/a cudes/media/anual?data=2013-1-1 $>$. Acesso em: 26 mar. 2016.

Lacerda, A. V.; Barbosa, F. M.; Vasconcellos Barbosa, M. R. Estudo do componente arbustivo-arbóreo de matas ciliares na Bacia do Rio Taperoá, semi-árido paraibano: uma perspectiva para a sustentabilidade dos recursos naturais. Oecologia Brasiliensis, v. 11, n. 3, p. 331-340, 2007.
Marques, M. C. V.; Barbosa, L. M. Manual para recuperação de áreas degradadas em matas ciliares do Estado de São Paulo. Marília: FAPESP/IBT/GEF, 2006.

Martins, S. V. Recuperação de matas ciliares. Viçosa: Aprenda Fácil, 2001.

MMA - Ministério do Meio Ambiente. Avaliação e ações prioritárias para a conservação da biodiversidade da Caatinga. Brasil. Recife: Universidade Federal de Pernambuco, Fundação de Apoio ao Desenvolvimento, Fundação Biosiversitas, EMBRAPA/Semi-Árido, MMA/SBF, 2002.

Rodrigues, R. R.; Leitão Filho, H. F. Matas ciliares, conservação e recuperação. São Paulo: EDEDUSP, 2000.

Santos, A. R.; Pacca, M. C. S.; Barros Filho, F. R. Mata ciliar e o novo código florestal. Anais JICEX, v. 2, n. 2, p. 1, 2013.

Silva, J. M. C.; Tabarelli, M.; Fonseca, M. T.; Lins, L. V. Biodiversidade da Caatinga: áreas e ações prioritárias para a conservação. Brasília: Ministério do Meio Ambiente, 2004.

Silva, R. M. P.; Lima, J. R.; Mendonça, I. F. C. Alteração da cobertura vegetal na Sub-Bacia do Rio Espinharas de 2000 a 2010. Revista Brasileira de Engenharia Agrícola e Ambiental, v. 18, n. 2, p. 202-209, 2014.

Sousa, R. F.; Barbosa, M. P.; Silva, M. J.; Fernandes, M. F. Avaliação das classes de cobertura vegetal e do uso das terras do Sítio Agreste - Itaporanga PB. Anais XIII Simpósio Brasileiro de Sensoriamento Remoto, Florianópolis, Brasil, 2007.

Vieira, R. M. S. P.; Cunha, A. P. M. A.; Alvalá, R. C. S.; Carvalho, V. C.; Ferraz Neto, S.; Sestini, M. F. Land use and land cover map of a Semiarid Region of Brazil for meteorological and climatic models. Revista Brasileira de Meteorologia, v. 28, n. 2, p. 129-138, 2013. http://dx.doi.org/10.1590/S010277862013000200002

Informação da Licença: Este é um artigo Open Access distribuído sob os termos da Licença Creative Commons AtribuiçãoSemDerivações-SemDerivados, que permite o download do trabalho e o compartilhamento desde que seja atribuído o devido crédito, mas sem que possa ser alterado de nenhuma forma ou utilizá-los para fins comerciais. 